\title{
JUSTIÇA TRIBUTÁRIA COMO PRESSUPOSTO DA JUSTIÇA SOCIAL
}

\author{
Ana Kátia Barbosa Torres \\ Concludente do curso de Especialização em Direito Tributário (FA7), \\ orientada pelo Prof. Dr. Hugo de Brito Machado Segundo (UFC). \\ Advogada. \\ akbtorres@yahoo.com.br
}

Sumário: Introdução. 1. O estado e o poder de tributar. 2. Análise da justiça tributária a partir dos princípios da isonomia e da capacidade contributiva. 3. Justiça social a partir da justiça tributária. Conclusão.

Resumo: O presente artigo debruça-se sobre o atual sistema tributário brasileiro, explicitando a intrínseca relação entre Justiça Tributária e Justiça Social e investigando a relação entre a insatisfação social com o sistema tributário nacional e a incapacidade estatal de atender as demandas sociais. Confronta-se tal sistema com os princípios da capacidade contributiva e da isonomia tributária, expõe-se sua natureza predominantemente regressiva, bem como se propõem à progressividade, à proba e efetiva destinação dos recursos tributários, notadamente os advindos das contribuições, e o aumento da participação política dos cidadãos como desafios para o alcance de uma maior justiça tributária e social.

Palavras-chave: Justiça Tributária. Princípio da isonomia. Princípio da capacidade contributiva. Justiça Social.

\section{INTRODUÇÃO}

Há muito a sociedade brasileira questiona a justiça do sistema tributário nacional, a elevada carga tributária, a guerra fiscal e o arrocho ao contribuinte, não sendo inédito afirmar que no Brasil há grande opressão da tributação sobre o cidadão comum e sobre as atividades produtivas.

A voracidade do sistema tributário, contudo, não guarda equivalência quantitativa e qualitativa com as ações sociais do Poder Público, de forma a cumprir os direitos sociais previstos na Constituição de 1988.

Daí surgem diversas questões a serem analisadas, a fim de responder se haveria relação entre a insatisfação da sociedade com o sistema tributário nacional e a incapacidade do Poder Público de atender de forma satisfatória às demandas sociais, bem como se a alegada injustiça na captação de tributos estaria entre as causas de um quadro de injustiça e desigualdades sociais, notadamente naquelas áreas mais sensíveis e críticas para o bem-estar da população, as que envolvem os direitos sociais previstos no art. $6^{\circ}$ da Constituição da República.

Correlacionam-se a essas questões, a própria averiguação da compatibilidade do sistema de captação de tributos com os princípios constitucionais tributários - mormente os 
princípios da isonomia e da capacidade contributiva -, a discussão acerca da função (regressiva ou progressiva) dos tributos, o debate acerca da espécie tributária mais apta ao alcance da redução das desigualdades, bem como se a busca pela justiça social não passaria pela aplicação mais transparente dos recursos tributários.

Com efeito, há muito vem se criticando o viés predominantemente regressivo do sistema tributário brasileiro. Paralelamente, a população também almeja uma maior justiça na arrecadação tributária, bem como uma proba e efetiva destinação dos recursos auferidos pelo Fisco, notadamente os advindos das chamadas contribuições, mais diretamente ligadas ao custeio de determinados direitos sociais.

O presente artigo versará, portanto, sobre a realidade do sistema tributário brasileiro, a fim de aferir se suas características são condizentes com o ideal de Justiça Tributária e da Justiça Social.

Analisar-se-á o sistema tributário como um todo, não havendo preocupação em fragmentar o estudo desse dito sistema a partir de determinado ente institucional dotado de competência e/ou capacidade tributária.

O estudo também não pretende fazer uma análise de modelos tributários experimentados em outros momentos histórico-constitucionais, muito menos a análise de modelos ainda em gestação e discussão (reforma tributária). Pautar-se-á apenas pelo sistema vigente, de forma a perceber os desafios necessários para o alcance de uma autêntica Justiça Tributária e de uma maior Justiça Social.

\section{O ESTADO E O PODER DE TRIBUTAR}

O combate à desigualdade é tarefa a ser perseguida por todos, a ponto de a Constituição da República Federativa do Brasil, em seu art. $3^{\circ}$, inciso III, ter constituído como um de seus objetivos "erradicar a pobreza e a marginalização e reduzir as desigualdades sociais e regionais".

O Estado Brasileiro, como instrumento de exercício do poder que emana do povo (art. $1^{\circ}$, parágrafo único da $\mathrm{CF} / 88$ ), detém a condução de todas as políticas públicas destinadas ao cumprimento dos comandos constitucionais.

Para promover o bem coletivo e atender às demandas sociais, o Estado se utiliza, preponderantemente, dentre outros meios financeiros e econômicos, do poder de tributar, poder este que se encontra constitucionalmente demarcado pelas chamadas limitações ao poder de tributar previstas na Seção II do Capítulo I (Do sistema tributário nacional) do Título VI (Da tributação e do orçamento) da Constituição Cidadã.

A tributação conduzida pelo Estado e suportada pelos cidadãos-contribuintes, antes de ser um meio de prover e manter a máquina estatal, é primariamente um dever de solidariedade social, dever este que possui natureza de princípio constitucional, conforme defende Machado (2010, p. 50):

A solidariedade social não é apenas uma ideia. É um princípio de nosso Direito Positivo, pelo menos a partir da Constituição Federal de 1988, que o alberga expressamente em dispositivo segundo o qual constituem objetivos fundamentais de nossa República "construir uma sociedade livre, justa e solidária" (art. $\left.3^{\circ}, \mathrm{I}\right)$.

Essa solidariedade, que permeia todo o sistema constitucional, decorre igualmente do modelo econômico adotado pelo constituinte, que preza pela propriedade privada e pela liberdade de iniciativa, gerando, inevitavelmente, desequilíbrios sociais, pois nem todos detêm os meios econômicos de produção. 
Cabe ao Estado, portanto, através do poder de tributar, corrigir as mazelas advindas de tal modelo, conforme apregoa Rosso (2009, p. 268):

\begin{abstract}
Por mais surpreendente que possa parecer ao analista superficial, o direito de tributar nasce, justamente, da opção da Constituição brasileira pela liberdade de iniciativa e proteção à propriedade privada (art. $5^{\circ}$, XXII e XXIII, da CF/1988). O caminho adotado pela Constituição, entretanto, implica em compromissos em sentido contrário: o Estado Fiscal não prescinde do combate à injustiça social ocasionada pela liberdade de iniciativa. Cabe ao Estado, ao aceitar a liberdade de iniciativa, remediar os desequilíbrios por ela ocasionados.
\end{abstract}

Já Mota (2010, pp. 200-201), distanciando-se da premissa de que as desigualdades nascem, por si mesmas, da liberdade de iniciativa concedida pelo Estado aos particulares, atenta para o uso instrumental do Direito Tributário para a realização da justiça social:

\footnotetext{
Cada sociedade, em cada realidade histórica própria, deve indicar e compor a função social de cada Estado. No Brasil, a busca das justiças social, tributária e fiscal foi imposta pela Constituição e a função social deve ser entendida como a principal função do Estado brasileiro atual para a realização da justiça social.
}

O mesmo autor (Mota, 2010, p. 201) também alerta para a necessidade de enxergar no tributo não só sua função fiscal, arrecadatória, mas também sua função ética, enquanto mecanismo utilizado pelo ente estatal - na qualidade de criação da sociedade -, para buscar implementar a justiça social:

\begin{abstract}
Portanto, a tributação no Brasil atual não mais deve ser considerada um mero instrumento de geração de recursos para o Estado, mas um instrumento que, embora tenha esse objetivo mediato, 'deve estar em sintonia com os demais objetivos constitucionais'.

A finalidade (objetivo, fim a que se destina o tributo) buscada pelo legislador infraconstitucional impõe dever o tributo na atualidade cumprir indiretamente uma função (ação, utilidade para consecução de seus objetivos) que caberia diretamente ao Estado contemporâneo cumprir: a função social. Dessa forma, o tributo na atualidade é instrumento de alcance daquela função social do Estado e, ao mesmo tempo, também cumpre sua função social.
\end{abstract}

Não se pretende afirmar que a Justiça Social no Brasil pode ser alcançada, unicamente, por uma maior Justiça Tributária, haja vista que a injustiça social brasileira tem como principal motor a má distribuição de renda, a qual envolve inúmeros fatores culturais e históricos negativos que não podem ser ignorados.

Mesmo assim, entende-se que o Estado, ao atuar como gestor das riquezas nacionais e como instrumento político de implementação dos direitos e garantias constitucionais, utiliza-se do poder de tributar como uma das principais ferramentas para o desenvolvimento do ideal de solidariedade social. Daí a íntima ligação entre uma necessária Justiça Tributária e uma almejada Justiça Social.

\title{
2 Análise da Justiça Tributária a Partir dos Princípios da Isonomia E da CAPACIDAde Contributiva
}

É necessário analisar se o sistema tributário vigente no Brasil é, por si só, justo a ponto de conduzir ou de propiciar maior justiça nas relações sociais.

A resposta a tal questionamento não pode desconsiderar a confrontação do próprio sistema ao conjunto de limitações ao poder de tributar presentes em nossa Constituição, notadamente os limites de natureza principiológica, especialmente os princípios da isonomia tributária e da capacidade contributiva. 
Segundo o administrativista Celso Antônio Bandeira de Mello,

princípio é, por definição, mandamento nuclear de um sistema, verdadeiro alicerce dele, disposição fundamental que se irradia sobre diferentes normas compondo-lhes o espírito e servindo de critério para sua exata compreensão e inteligência exatamente por definir a lógica e a racionalidade do sistema normativo, no que lhe confere a tônica e lhe dá sentido harmônico. É o conhecimento dos princípios que preside a intelecção das diferentes partes componentes do todo unitário que tem por nome sistema jurídico positivo (Mello, 2003, pp. 817-818)

Nesse sentido, as exações tributárias hão de ser compreendidas a partir da lógica unitária principiológica do sistema tributário nacional, a fim de verificar se essas mesmas exações atingem as finalidades almejadas pelo próprio ordenamento.

A isonomia tributária, umbilicalmente ligada ao valor supremo da igualdade previsto no caput do art. $5^{\circ}$ da Constituição Federal de 1988, é um parâmetro indispensável à aferição da justiça tributária, estando insculpida no inciso II do art. 150 do texto constitucional:

Art. 150. Sem prejuízo de outras garantias asseguradas ao contribuinte, é vedado à União, aos Estados, ao Distrito Federal e aos Municípios:

(...)

II - instituir tratamento desigual entre contribuintes que se encontrem em situação equivalente, proibida qualquer distinção em razão de ocupação profissional ou função por eles exercida, independentemente da denominação jurídica dos rendimentos, títulos ou direitos;

Tal valor liga-se de forma profunda ao próprio sistema republicano, consoante preleciona Carrazza (2006, p. 78):

De fato, o princípio republicano exige que os contribuintes (pessoas físicas ou jurídicas) recebam tratamento isonômico.

A lei tributária deve ser igual para todos e a todos deve ser aplicada com igualdade. Melhor expondo, quem está na mesma situação jurídica deve receber o mesmo tratamento tributário. Será inconstitucional - por burla ao princípio republicano e ao da isonomia - a lei tributária que selecione pessoas, para submetê-las a regras peculiares, que não alcançam outras, ocupantes de idênticas posições jurídicas.

O tributo, ainda que instituído por meio de lei, editada pela pessoa política competente, não pode atingir apenas um ou alguns contribuintes, deixando a salvo outros que, comprovadamente, se achem nas mesmas condições.

Já Velloso (2007, p. 47), referindo-se, inclusive, ao ordenamento jurídico alemão, evidencia a imediata conexão da ideia da isonomia com a realização da justiça:

A determinação do conteúdo do princípio da isonomia envolve, portanto, uma questão de justiça (Gerechtigkeitsfrage), pois deverá ser realizada à luz dos valores essenciais aos Estados Constitucionais de Direito, os quais constituem, sem sombra de dúvidas, expressões jurídico-constitucionais do núcleo essencial das teorias de justiça. Por isso é viável afirmar, com Weinberger, que a igualdade material é "isonomia segundo pontos de vista de justiça" (Gleichheit nach Gerechtigkeitsgesichtspunkten) e, via de consequência, que o princípio de igualdade, constitui um mandado de justiça (Gerichtkeitsgebot). Determina que se adotem tratamentos jurídicos justos ou, mais precisamente, que se efetuem juízos de igualdade fundados sobre critérios de justiça e se estabeleçam tratamentos jurídicos conformes a tais juízos.

A concreção do mandamento da igualdade pressupõe, todavia, a utilização da lógica da isonomia, segundo a qual se devem tratar igualmente os iguais e desigualmente os desiguais, na medida das suas desigualdades.

Bem se vê, portanto, que o tratamento isonômico, para realizar a igualdade, requer a identificação de um justo e viável fator discriminatório, tarefa bastante árdua segundo a visão de José Eduardo Soares de Melo: 
Deveras problemático, tormentoso, intrincado e difícil precisar o conceito e os limites da igualdade, o tratamento isonômico a ser observado pelo legislador que não pode discriminar arbitrariamente, devendo observar o requisito constitucional da correlação lógica entre o fator do discrímen e a diferenciação consequente (Melo, 2010, p. 29).

A fim de adotar tratamentos tributários diferenciados, porém justos, deve-se verificar a consonância do fator discriminatório com os interesses protegidos constitucionalmente. Tal verificação só se efetiva, segundo o jurista Celso Antônio Bandeira de Mello, quando há a concorrência de quatro elementos, quais sejam:

a) que a desequiparação não atinja de modo atual e absoluto, um só indivíduo;

b) que as situações ou pessoas desequiparadas pela regra de direito sejam efetivamente distintas entre si, vale dizer, possuam características, traços, nelas residentes, diferenciados;

c) que exista, em abstrato, uma correlação lógica entre os fatores diferenciais existentes e a distinção de regime jurídico em função deles, estabelecida pela norma jurídica;

d) que, in concreto, o vínculo de correlação supra-referido seja pertinente em função dos interesses constitucionalmente protegidos, isto é, resulte em diferenciação de tratamento jurídico fundada em razão valiosa - ao lume do texto constitucional - para o bem público (Mello, 2011, p. 41).

No ordenamento jurídico brasileiro, a busca pelo fator discriminatório quadripartite apto a conferir tratamento isonômico realizador da igualdade gravita ao redor do princípio da capacidade contributiva, previsto no art. $145, \S 1^{\circ}$ da Constituição da República:

e) $\S 1^{\circ}$ - Sempre que possível, os impostos terão caráter pessoal e serão graduados segundo a capacidade econômica do contribuinte, facultado à administração tributária, especialmente para conferir efetividade a esses objetivos, identificar, respeitados os direitos individuais e nos termos da lei, o patrimônio, os rendimentos e as atividades econômicas do contribuinte.

Tal princípio é considerado por Carrazza (2006, p. 86) como “um dos mecanismos mais eficazes para que se alcance a tão almejada Justiça Fiscal", instrumentalizando a igualdade republicana:

f) O princípio da capacidade contributiva hospeda-se nas dobras do princípio da igualdade e ajuda a realizar, no campo tributário, os ideais republicanos. Realmente, é justo e jurídico que quem, em termos econômicos, tem muito pague, proporcionalmente, mais imposto do que quem tem pouco. Quem tem maior riqueza deve, em termos proporcionais, pagar mais imposto do que quem tem menor riqueza. Noutras palavras, deve contribuir mais para a manutenção da coisa pública. As pessoas, pois, devem pagar impostos na proporção dos seus haveres, ou seja, de seus índices de riqueza (Carrazza, 2006, p. 86).

Segundo Baleeiro (2006, p. 276), a capacidade contributiva, inseparável da também constitucional vedação do confisco, representa "sua idoneidade econômica para suportar, sem sacrifício do indispensável à vida compatível com a dignidade humana uma fração qualquer do custo total de serviços públicos".

As considerações acima permitem concluir, portanto, que o fator de discrímen, segundo a capacidade contributiva, é o poder econômico de cada contribuinte em potencial, manifestado pelo fato imponível.

É importante ressaltar que, segundo a letra fria do $\S 1^{\circ}$ do art. 145 da Constituição Federal, a graduação econômica da tributação segundo a lógica da capacidade contributiva, baseada no critério da riqueza econômica do contribuinte, se circunscreveria aos tributos-impostos, e não a todas as espécies tributárias.

Tal interpretação, contudo, é alvo de críticas substanciais por parte da doutrina, que estende a ideia da capacidade contributiva não somente aos impostos, mas a todas as espécies de tributo.

É o que defende José Eduardo Soares de Melo: 
A capacidade contributiva deveria estar subjacente em qualquer espécie tributária, revelada pelo valor do objeto (materialidade). Tendo em vista que a tributação quantifica-se por uma base de cálculo (a qual se aplica uma alíquota), salvo os casos excepcionais de tributo fixo, e como esta nada mais é do que o próprio valor (econômico) da materialidade, sempre será possível medir a intensidade (econômica) de participação do contribuinte no montante do tributo.

\section{(...)}

Observa-se que a capacidade contributiva não se refere apenas a impostos (art. 145, $\S 1^{\circ}$ ), pois é possível inferir sua aplicação às taxas (art. $5^{\circ}$, LXXIV e LXXVII, da Constituição), no caso de o Estado ser obrigado a prestar assistência integral e tornar gratuito o registro civil de nascimento e certidão de óbito, aos que comprovarem insuficiência de recursos. Trata-se de situações excepcionais, uma vez que as taxas levam em consideração os custos dos serviços públicos, e não, particularmente, a situação patrimonial/econômica do beneficiário.

O princípio é aplicável, também, às contribuições sociais que tenham materialidades pertinentes aos impostos, tais como a Cofins (art. 195, I, b, da CF) e o PIS (art. 239 da CF) relativamente ao faturamento e à receita (Melo, 2010, pp. 32-33).

O que se extrai do sistema tributário brasileiro, entretanto, é que o ideal de justiça tributária, que seria produto dos valores da igualdade e da capacidade contributiva impostos pela Constituição, está bem distante da realidade almejada.

\section{JustiçA SOCIAL A PARTIR DA JUSTIÇA TRIBUTÁRIA}

Conforme afirmou-se anteriormente, seria risível afirmar que a Justiça Social no Brasil pode ser debelada, exclusivamente, por uma maior Justiça Tributária. A injustiça social brasileira tem múltiplas e complexas causas.

Entretanto, defende-se que o Estado, ao atuar como gestor das riquezas nacionais e como ente político responsável pela concretização dos direitos e garantias constitucionais, deve usar o poder de tributar como meio para alcançar uma maior justiça no meio social, impulsionado por seu objetivo institucional de erradicar a pobreza e a marginalização e reduzir as desigualdades sociais e regionais.

Grande parte da doutrina elenca como principal empecilho ao alcance de uma maior justiça social a partir da justiça tributária, o fato de que o sistema tributário nacional é eminentemente regressivo e apenas ocasionalmente progressivo. essas variáveis:

Machado Segundo (2009, pp. 216-217) demonstra claramente o que significam

Considera-se progressivo o tributo cujo ônus é tanto maior quanto maior for a grandeza econômica tributável, o que faz com o que o seu montante não seja apenas proporcionalmente maior, mas progressivamente maior. Quem tem mais, paga sensivelmente mais, considerando-se a chamada utilidade marginal de riqueza.

(...)

A tributação regressiva, por sua vez, consiste precisamente no contrário da progressiva. O ônus do tributo é tanto menor quanto maior for a grandeza tributada, o que faz com que as pessoas dotadas de menor capacidade contributiva suportem, proporcionalmente, uma carga tributária muito maior.

O mesmo autor exemplifica a aplicação dessas duas características:

Ao onerar com uma alíquota de 10\% salário de R $\$ 500,00$ mensais, por exemplo, retira-se do patrimônio do contribuinte quantia que lhe fará seguramente muita falta no atendimento de suas necessidades básicas. O mesmo percentual de 10\%, incidente sobre um salário de $\mathrm{R} \$$ 5.000,00 faria também falta ao empregado, mas, embora a proporção seja a mesma, essa falta seria menor. Em se tratando de um salário de R \$100.000,00, 10\% já não fariam praticamente falta nenhuma. É essa utilidade, cada vez menor, que a riqueza tem para quem a acumula, que justifica, por imposição dos princípios da isonomia e da capacidade contributiva, uma tributação progressiva (Machado Segundo, 2009, p. 217). 
Pochmann (2008), dentro de um estudo dirigido pelo Instituto de Pesquisa Econômica Aplicada (IPEA), quantifica a desigualdade provocada pela preponderância da regressividade do sistema tributário nacional:

A Carga Tributária Bruta é constituída por tributos diretos - que incidem sobre a renda e o patrimônio - e por tributos indiretos - que incidem sobre o consumo. É sabido que a tributação indireta têm características regressivas, isto é, incidem mais sobre os mais pobres, enquanto que a tributação direta possui efeitos mais progressivos, incidindo mais sobre os mais ricos.

O Gráfico acima confirma essa regra geral para o Brasil, mas com um grave problema: o peso da tributação indireta é muito maior do que o da tributação direta, tornando regressivo o efeito final do nosso sistema tributário. Ademais, o grau de progressividade da tributação direta ainda é baixo no Brasil. O décimo mais pobre sofre uma carga total equivalente a $32,8 \%$ da sua renda, enquanto o décimo mais rico, apenas 22,7. Isto é absolutamente inaceitável, principalmente em um país de enorme desigualdade de renda como o Brasil.

A partir desse mesmo estudo, Leal (2012, p. 25) usa de certa ironia para qualificar a matriz tributária brasileira:

\begin{abstract}
A matriz tributária brasileira - em paradoxal incoerência com os princípios e objetivos fundamentais da República instituída pela Constituição de 1988 - é cruelmente regressiva, o que significa dizer que, em boa medida, quem tem menos capacidade contributiva paga um percentual maior a título de tributos.

Em outras palavras, o sistema tributário brasileiro, globalmente considerado, funciona como uma espécie de Robin Hood às avessas: tira dos pobres para dar para os ricos; isto é, redistribui riqueza dos mais necessitados para os mais afortunados.
\end{abstract}

A partir dessas considerações, podemos afirmar que conferir efeito progressivo à tributação é um dos principais desafios ao alcance de uma maior justiça na arrecadação dos tributos e um instrumento indispensável à realização da igualdade social e tributária.

A par da existência desse efeito progressivo em algumas espécies tributárias em nosso ordenamento jurídico, tais como o IPTU (Imposto sobre Propriedade Predial e Territorial Urbana), o ITR (Imposto sobre Propriedade Territorial Rural) e o IR (imposto de Renda), entende-se que tal efeito pode ser sim estendido a outros tributos.

Há quem defenda, inclusive, que não existe obstáculo constitucional à aplicação desse efeito a todas as espécies tributárias:

Não trato aqui, portanto, das previsões constitucionais de progressividade em relação a alguns
tributos, como quando a Constituição cuida do Imposto de Renda e do Imposto Territorial
Rural (art. 153), ou ainda quando faculta a progressividade do IPTU em razão do valor do
imóvel e da função social da propriedade (art. 156), mas da obrigação constitucional mesma
de se estabelecer um sistema tributário que seja, no todo, progressivo (Alves, 2009, p. 1).

Com efeito, a progressividade dos tributos é uma consagração da isonomia e do princípio da capacidade contributiva. Torres (2005, p. 312) chega a colocá-la como subprincípio da capacidade contributiva.

Nesse raciocínio, partindo da premissa de que se admita, ou pelo menos se deseje, que o Princípio da Capacidade Contributiva se aplique a todas as espécies tributárias, e não somente aos impostos, como defende Machado (Machado, 2010, p. 45), a técnica da progressividade, por ser seu subprincípio, deveria ser observada em todos os tributos.

Ocorre que o ordenamento ainda hesita em aceitar tal conclusão sem reservas, existindo sérias dificuldades na aplicação da progressividade em tributos que onerem a renda, o patrimônio e, principalmente, o consumo.

Muitos entendem que a aplicação da técnica requer expressa previsão constitucional, o que acaba por esvaziar a ideia da progressividade como corolário da capacidade contributiva. 
Outros defendem que a aplicação da progressividade - como nos casos do IPTU (Imposto sobre Propriedade Predial e Territorial Urbana), ITR (Imposto sobre Propriedade Territorial Rural) e IR (imposto de Renda) - teria conotação extrafiscal, e não poderia ser compreendida como consagração da capacidade contributiva.

Paralelamente, resiste-se à aplicação da progressividade sobre os chamados impostos reais. Seus detratores defendem que somente nos impostos de natureza pessoal é possível aferir a capacidade contributiva do indivíduo.

Em relação aos impostos que oneram o consumo, marcadamente regressivos, até mesmo em face de sua característica plurifásica, observa-se que a implantação da técnica da progressividade tem esbarrado, como bem defende (Calciolari, 2007, p. 219), na indisposição política, somada às problemáticas federalistas.

Tais considerações, portanto, permitem concluir que os entraves legislativos, políticos e interpretativos acerca da aplicação da técnica da progressividade perpetuam a injustiça na arrecadação de tributos, mantendo-a precipuamente regressiva e, consequentemente, não permitindo que se aplaque a injustiça no meio social.

A par da problemática que envolve a regressividade-progressividade dos tributos, não se pode deixar de considerar o papel ímpar das chamadas contribuições para o alcance de uma maior justiça social.

Tal espécie tributária, cuja instituição, nos termos do art. 149 da Constituição Federal, compete exclusivamente à União, tem em sua própria gênese a característica de ser instrumentalizadora de finalidades sociais expressamente delimitadas na Constituição Federal, como a seguridade social, por exemplo.

Mas há que se considerar que o incremento dessa espécie sui generis de tributo, por si só, não basta.

É necessário lutar por uma aplicação proba, transparente e eficaz dos recursos tributários obtidos pelo Estado - inclusive as contribuições - no atendimento de direitos sociais mínimos da população, como a saúde, a educação e a alimentação, ou seja, para a satisfação dos direitos sociais comtemplados no caput do art. $6^{\circ}$ da Constituição da República:

Art. $6^{\circ}$ São direitos sociais a educação, a saúde, a alimentação, o trabalho, a moradia, o lazer, a segurança, a previdência social, a proteção à maternidade e à infância, a assistência aos desamparados, na forma desta Constituição.

Além disso, urge que a sociedade brasileira também discuta o alargamento da vinculação das receitas tributárias em detrimento da discricionariedade obscura da Administração Pública.

Tais desafios, segundo Machado Segundo (2009, pp. 229-230), só serão realmente enfrentados a partir de um incremento da participação política dos cidadãos brasileiros na gerência das riquezas nacionais, não somente através da eleição de representantes, mas sim na esteira do ideal da democracia participativa, pela participação direta do povo na vida política e no controle dos orçamentos e dos gastos públicos.

\section{Conclusão}

Em razão do que foi exposto anteriormente, podem ser apontadas as seguintes conclusões:

a) o Estado brasileiro, enquanto ente criado pelo meio social para atender seus interesses primordiais, expressos, hodiernamente, na Constituição Federal de 1988, tem, no poder de tributar, 
um dos principais instrumentos na concreção desses mesmos anseios, notadamente os direitos sociais previstos no art. $6^{\circ}$ da Constituição da República;

b) o ideal de justiça social, portanto, pressupõe que haja justiça tributária na sociedade, de sorte que as demandas mais críticas da população - os direitos socialmente assegurados na Constituição Federal de 1988 - só podem ser implementadas de forma mais eficaz se houver maior justiça tanto no processo de arrecadação como na destinação dos recursos tributários, que compõem a fração de maior expressividade dentre os recursos financeiros do Estado;

c) a aferição da justiça do sistema tributário, enquanto meio de realização da justiça social, tem como parâmetros inafastáveis as limitações ao poder de tributar, presentes em nossa Constituição, notadamente os limites de natureza principiológica, especialmente os princípios da isonomia tributária e da capacidade contributiva;

d) a realização da igualdade tributária perpassa pela adoção de tratamentos tributários diferenciados, segundo a máxima da isonomia, de forma que o fator discriminatório, para ser justo, deve estar em consonância com os interesses protegidos constitucionalmente. A delimitação desse fator de discrímen gravita ao redor do princípio da capacidade contributiva, segundo o qual a manutenção da coisa pública deve partir de uma tributação que seja proporcionalmente graduada segundo a capacidade econômica dos contribuintes;

e) ainda não há consenso na doutrina acerca da abrangência do princípio da capacidade contributiva, haja vista que, enquanto uns apontam que só se aplica aos impostos, outros defendem que deve ser estendida a todas as espécies trributárias;

f) o sistema tributário brasileiro é esmagadoramente regressivo, provocando grande injustiça tributária e social, pois impinge às pessoas de menor capacidade contributiva um peso bem superior àquele carregado pelos que tem maior poder econômico;

g) a técnica da progressividade, que garante que o ônus tributário seja maior quanto maior for a grandeza econômica tributada, constitui o principal desafio para que se alcance uma maior justiça tributária e social. Todavia, o ordenamento, em face de entraves legislativos, políticos e interpretativos, ainda hesita em aceitar tal conclusão, o que acaba por esvaziar a ideia da progressividade como corolário da capacidade contributiva;

h) a justiça social, por fim, pressupõe a proba e efetiva destinação dos recursos auferidos pelo Fisco, notadamente os advindos das chamadas contribuições, mais diretamente ligadas ao custeio de determinados direitos sociais, e o alargamento da vinculação das receitas tributárias em detrimento da discricionariedade obscura da Administração Pública, desafios que requerem um incremento da participação política dos cidadãos brasileiros na gerência das riquezas nacionais, não somente através da eleição de seus representantes, mas também conforme o ideal da democracia participativa, pela participação efetiva do povo na vida política, no controle dos orçamentos e dos gastos públicos.

\section{REFERÊNCIAS}

ALVES, Henrique Napoleão. Tributação está na contramão dos Direitos Humanos. São Paulo: Revista Consultor Jurídico, 25 de agosto de 2009. Disponível em: http://www.conjur.com.br/2009-ago-25/tributacao-regressiva-contramao-direitos-humanos. Acesso em 15.ago.2010.

BALEEIRO. Aliomar. Uma introdução à ciência das finanças. 16 ed. atual. por Dejalma de Campos. Rio de Janeiro: Forense, 2006.

BRASIL. Constituição (2010). Constituição da República Federativa do Brasil. Brasília: DF, Senado, 1988. 
CALCIOLARI, Ricardo Pires. Progressividade tributária, segurança e justiça fiscal. Revista Tributária e de Finanças Públicas, São Paulo, Ano 15, n. 76, pp. 198-225, set./out.2007.

CARraZZA, Roque Antonio. Curso de Direito Constitucional Tributário. 22. ed. rev. atual. ampl. São Paulo: Malheiros, 2006.

LEAL, Augusto César de Carvalho. (In)Justiça Social por Meio dos Tributos: a Finalidade Redistributiva da Tributação e a Regressividade da Matriz Tributária Brasileira. Revista Dialética de Direito Tributário, São Paulo, n. 196, pp. 07-32, jan. 2012.

MACHADO, Hugo de Brito. Curso de Direito Constitucional Tributário. 31. ed. rev. atual. ampl. São Paulo: Malheiros, 2010.

MACHADO, Hugo de Brito Segundo. Fundamentos do ordenamento jurídico: liberdade, igualdade e democracia como premissas necessárias à aproximação de uma justiça possível. 2009. 266f. Tese (Doutorado em Direito Constitucional) - Programa de Pós-Graduação em Direito Constitucional-Doutorado. Universidade de Fortaleza, Belo Horizonte, 2009.

MELO, José Eduardo Soares de. Curso de Direito Tributário. 9. ed. São Paulo: Dialética, 2010. MELlo, Celso Antônio Bandeira de. Curso de Direito Administrativo. 15 ed. São Paulo: Malheiros, 2003.

. O conteúdo jurídico do princípio da igualdade. 3. ed. São Paulo: Malheiros, 2011.

MOTA, Sérgio Ricardo Ferreira. Justiças social, tributária e fiscal no Brasil: uma busca imposta pela Constituição. Revista Tributária e de Finanças Públicas, São Paulo, Ano 18, n. 93, pp. 199-217, jul./ago.2010.

POCHMANN, Márcio. Desigualdade e Justiça Tributária. Brasília: IPEA, 15 de maio de 2008. 2008. Disponível em: <http://oglobo.globo.com/blogs/arquivos_upload/2008/05/197_1548-DesigualdadeJusticaTributaria-CDES.pdf. Acesso em: 15.ago.2010.

ROSSO, Paulo Sérgio. Tributação e solidariedade no Estado brasileiro. Revista Tributária e de Finanças Públicas, São Paulo, Ano 17, n. 85, pp. 259-272, mar./abr2009.

TORRES, Ricardo Lobo. Tratado de direito constitucional financeiro e tributário: valores e princípios constitucionais tributários. Rio de Janeiro: Renovar, 2005.

VELLOSO, Andrei Pitten. A teoria da igualdade tributária e o controle de proporcionalidade das desigualdades de tratamento. Revista Tributária e de Finanças Públicas, São Paulo, Ano 15, n. 76, pp. 36-72, set./out.2007.

\section{TRIBUTARY JUSTICE AS SOCIAL JUSTICE}

Abstract: This article focuses on the current Brazilian tributary system, highlighting the intrinsic relationship between Tributary and Social Justice, or social dissatisfaction with the national tributary system and the inability of the state to meet the social demands. Such system is studied through the principles of contributive capacity and tributary isonomy.

Keywords: Tributary Justice. Isonomy Principle. Contributive Capacity Principle. Social Justice. 